\title{
DETERMINAÇÃO DE FATORES DE EMPILHAMENTO ATRAVÉS DO SOFTWARE DIGITORA ${ }^{1}$
}

\author{
Alexandre Bertola ${ }^{2}$, Carlos Pedro Boechat Soares ${ }^{3}$, José Carlos Ribeiro ${ }^{3}$, Helio Garcia Leite e $^{3}$ \\ Agostinho Lopes de Souza ${ }^{3}$
}

\begin{abstract}
RESUMO - Este trabalho foi realizado com o objetivo de avaliar o uso do programa computacional Digitora na determinação de fatores de empilhamento. Para isto, foram utilizadas pilhas de madeira de eucalipto, empilhadas manualmente sobre o solo. Após as análises, verificou-se que: a) o software propiciou estimativas precisas dos fatores de empilhamento; b) houve uma leve tendência de superestimação dos fatores pelo Digitora; c) o treinamento do operador com relação à classificação dos pontos sobre as fotografias no Digitora é condição primordial para obtenção de estimativas precisas dos fatores de empilhamentos; e d) as fotografias deverão ser sempre tomadas com oflash e o ZOOM ativados.
\end{abstract}

Palavras-chave: Fatores de empilhamento, eucalipto e fotografias digitais.

\section{DETERMINATION OF PILING FACTORS THROUGH DIGITORA SOFTWARE}

\begin{abstract}
The objective of this study was to evaluate the use of the Digitora software to obtain piling factors. Thus, stacks of eucalyptus wood were piled up manually on the soil. After the analyses, it was verified that: a) the Digitora software provided precise piling factor estimates; $b$ ) there was a slight tendency towards overestimating the factors by Digitora; $c)$ the operator training related to classification of the points on the photographs in Digitora is an essencial condition for obtaining precise piling factor estimates; d) the photographs should always be taken with activated flash and ZOOM.
\end{abstract}

Key words: $\quad$ Piling factors, eucalyptus, digital photographs.

\section{INTRODUÇÃO}

$\mathrm{O}$ volume sólido de madeira empilhada pode ser obtido pelo somatório dos volumes das toras de madeira na pilha, pela aplicação de expressões aproximativas na cubagem rigorosa, ou através do uso do xilômetro (Husch et al., 1972; Scolforo \& Filho, 1992). Porém, este método possui inconvenientes quando as pilhas de madeira são muito grandes ou quando as dimensões das toras são grandes, acarretando grande dispêndio de mão-de-obra e tempo para a execução do trabalho. Além destes métodos, o volume sólido de madeira empilhada pode ser obtido através de fatores de empilhamento, da pesagem das pilhas de madeira e da utilização de equações de regressão (Couto \& Bastos, 1988; Andrade \& Leite, 1998; Paula Neto \& Rezende, 1992), que são métodos cujas precisões podem variar consideravelmente, dependendo de como forem utilizados.

No Brasil, o uso de fatores de empilhamento é prática comum para conversão do volume de madeira empilhada em volume sólido de madeira. No entanto, características como os diâmetros e comprimentos das toras de madeira, a espessura da casca, a forma de empilhar, a espécie, a idade das árvores, entre outros fatores, afetam o volume de madeira empilhada, de tal forma que

1 Recebido para publicação em 29.5.2002.

Aceito para publicação em 4.11.2003.

2 Estudante de Mestrado em Ciência Florestal na Universidade Federal de Viçosa - UFV, Rua Voluntários da Pátria, 81, 35790-000 Curvelo-MG. ${ }^{3}$ Professores do Dep. de Engenharia Florestal da UFV, 36570-000 Viçosa-MG. 
a utilização de um fator médio resulta, às vezes, em erros nas estimativas (Zon, 1903; Association of Forest Engineers for the Province of Quebec, 1928; Schnur, 1932; Bruce \& Schumacher; 1950).

A determinação do fator de empilhamento pelo método tradicional, em inventários florestais, baseia-se na derrubada e no seccionamento das árvores contidas em parcelas representativas das condições da floresta (idade, espaçamento, qualidade do local etc.), com a finalidade de obter o volume sólido de madeira $\left(\mathrm{m}^{3}\right)$ e o volume empilhado em estéreo (st). Consequientemente, o fator de empilhamento médio do povoamento será a média aritmética dos fatores de cada pilha de madeira. Outra maneira de obter o fator de empilhamento é através do método fotográfico. Segundo Husch et al. (1972), neste método o fator de empilhamento é estimado através de fotos tiradas perpendicularmente às faces das pilhas. A foto é obtida, instalando-se ou mantendo-se uma câmera fotográfica a uma distância conveniente da pilha, em torno de 10 pés $(\cong 3,0 \mathrm{~m})$, com eixo óptico da lente perpendicular a uma de suas faces. Depois, coloca-se sobre a foto um "templet" (semelhante aos usados em aerofotogrametria), com cerca de 16 espaços ponteados por polegada quadrada $\left(\cong 6,5 \mathrm{~cm}^{2}\right)$, na escala de $1: 30$.

Garland (1968) relatou que não é necessário amostrar toda a face da foto. Uma amostra de apenas $20 \%$ dela é o suficiente. Assim sendo, conta-se o número de perfurações sobre os espaços e sobre as toras, de tal forma que a porcentagem de pontos que "caírem" sobre a madeira representa a área ocupada por madeira na face da pilha ou o fator de empilhamento.

Vários autores, dentre eles Mountain (1949), Keepers (1945) e Rubio (1982), mostraram que esse método pode ser aplicado para qualquer pilha de madeira, com o uso de uma câmera de 35 mm. Garland (1968) também mostrou como esse método pode ser aplicado em caminhões, com uma câmera Polaroid, a fim de calcular o volume sólido de madeira, de forma que os caminhoneiros possam ser pagos no local de descarga da madeira. No Brasil, Rezende (1988) verificou que o método fotográfico apresentou tendência de subestimação dos fatores de empilhamento em pilhas de madeira de eucalipto, acentuando-se em pilhas com toras de maiores diâmetros.

Embora o método de determinação de fatores de empilhamento através de fotografias seja uma alternativa viável, apresenta-se defasado na sua forma original, tendo em vista o desenvolvimento de novas tecnologias, que permitem operacionalizá-lo sem a necessidade de revelar os filmes

R. Árvore, Viçosa-MG, v.27, n.6, p.837-844, 2003 fotográficos e de elaborar templets em papéis especiais. Assim sendo, o objetivo deste trabalho foi avaliar o uso de fotografias digitais e um programa computacional especificamente desenvolvido para a determinação de fatores de empilhamento (DIGITORA), em substituição ao método tradicional de obtenção de fatores por fotografias.

\section{MATERIAL E MÉTODOS}

O presente estudo foi realizado no setor de Silvicultura da Universidade Federal de Viçosa (UFV), município de Viçosa, Estado de Minas Gerais. Foram utilizadas 30 pilhas de madeira de Eucalyptus grandis, empilhadas manualmente. Em cada pilha foram obtidos o volume real $\left(\mathrm{m}^{3}\right)$ e o volume em estéreo $(\mathrm{st})$, bem como tiradas fotos para determinação de fatores de empilhamento. Optou-se pela montagem de pilhas, utilizando um conjunto de toras suficientes para haver um rodízio, de tal maneira que nenhuma pilha teria o mesmo volume, o mesmo tamanho, nem as mesmas toras. Foram construídas pilhas de $3 \mathrm{~m}$ de comprimento $(\mathrm{C})$ e altura máxima (H) de $2 \mathrm{~m}$, sustentadas por estacas de madeira, que também serviram de apoio para as toras. A largura da pilha (L) ou profundidade da pilha correspondeu ao comprimento médio das toras, que foi de $1 \mathrm{~m}$ (Figura 1).

De posse do conjunto de toras de madeira, o volume com casca, em metro cúbico, de cada tora individualmente foi obtido pela aplicação da fórmula de Smalian:

$V_{i}=\frac{g_{i}+g_{s}}{2} . L$

em que $V_{i}=$ volume da i-ésima tora, com casca, em $\mathrm{m}^{3}$; $g i=$ área seccional com casca, correspondente à extremidade mais grossa da tora, $\mathrm{em}^{2} ; g s=$ área seccional com casca, correspondente à extremidade mais fina da tora, em $\mathrm{m}^{2}$; e $\mathrm{L}=$ comprimento da tora, em $\mathrm{m}$.

O volume sólido com casca de cada pilha de madeira foi obtido pelo somatório dos volumes das toras, individualmente.

O volume em estéreo de cada pilha foi obtido ao multiplicar as médias das alturas e dos comprimentos da pilha pelo comprimento médio das toras. Em cada pilha foram tomadas 20 medidas de altura (10 em cada face), para obter a altura média da pilha, bem como mediu-se o comprimento da pilha na base, na metade da altura da pilha e no topo, para obter o seu comprimento médio. $\mathrm{O}$ comprimento médio das toras em cada pilha foi obtido no procedimento de cubagem rigorosa. 
Os fatores de empilhamento com casca $(\mathrm{Fe})$, observados em cada pilha, foram obtidos pela expressão:

$F e=\frac{V c c(s t)}{\operatorname{Vcc}\left(m^{3}\right)}$

em que $\mathrm{Fe}=$ fator de empilhamento com casca; $V c c$ (st) $=$ volume da pilha com casca, em st; e $V c c\left(\mathrm{~m}^{3}\right)=$ volume da pilha com casca, em $\mathrm{m}^{3}$.

Os fatores de empilhamento com casca, estimados para cada pilha, foram obtidos mediante o emprego de um programa computacional denominado DIGITORA, desenvolvido pelo professor José Carlos Ribeiro, do Departamento de Engenharia Florestal de Viçosa, e pelo engenheiro civil José Carlos Lopes Ribeiro. A metodologia utilizada no software é a mesma descrita por Husch et al. (1972), porém as fotos não precisaram ser reveladas e nem houve a necessidade de elaboração de um templet de forma manual.

A tomada das fotos foi feita com uma câmera Kodak DC 210. As fotos foram tiradas com o observador posicionando-se a 3,0 m de cada face da pilha e com a câmera ajustada com ZOOM máximo, com a resolução de 1.152 x 864 dpi.

De posse das fotos, estas foram transferidas para o microcomputador e armazenadas para análises. Através de um comando do software, uma rede de aproximadamente 150 a 200 pontos, distantes entre si 20 pixels na horizontal e 15 pixels na vertical e cobrindo cerca de $50 \%$ da área da foto, foi exibida aleatoriamente sobre ela (cada face da pilha). Cada ponto foi observado (Figura 2) e classificado como:

- Pontos vazios: pontos projetados nos espaços vazios entre as toras.

- Pontos meio: pontos projetados metade sobre a tora e metade nos espaços vazios.

- Pontos anulados: pontos sobre áreas de difícil visualização.

Uma vez classificados os pontos sobre a foto, a porcentagem de área de madeira na face da pilha [Pm (\%)] foi calculada pela seguinte expressão:

$\operatorname{Pm}(\%)=\left(1-\frac{\text { vazios }+\frac{\text { meio }}{2}}{\text { total }- \text { anulados }}\right) * 100$
O fator de empilhamento com casca, obtido por:

$F_{e}=\frac{1}{\frac{P m(\%)}{100}}$

Com as fotos das duas faces da pilha e procedendose às operações descritas anteriormente, obteve-se o fator de empilhamento médio com casca para cada pilha, pela média aritmética dos dois fatores.

Para avaliar o efeito do operador na obtenção dos fatores de empilhamento no software DIGITORA, foram obtidas três estimativas de fatores para cada pilha: uma com um operador treinado com o software (operador 1) e duas com operadores não-treinados (operadores 2 e 3 ).

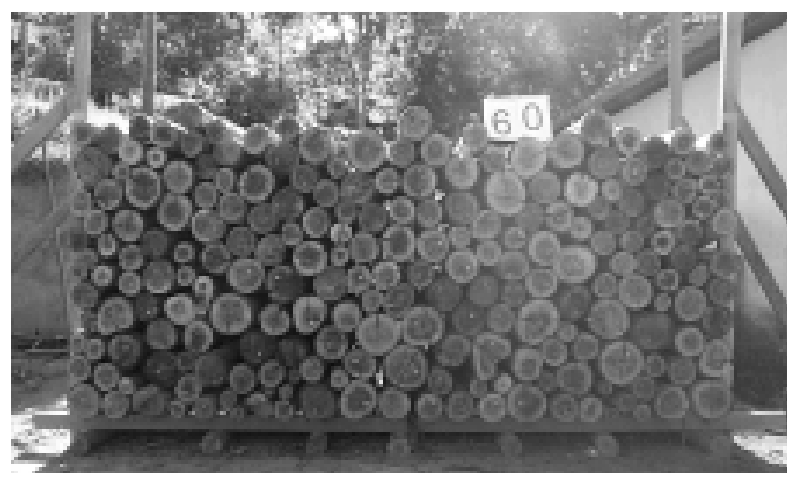

Figura 1 - Pilha de madeira de eucalipto. Figure 1 - Eucalypt wood stack.

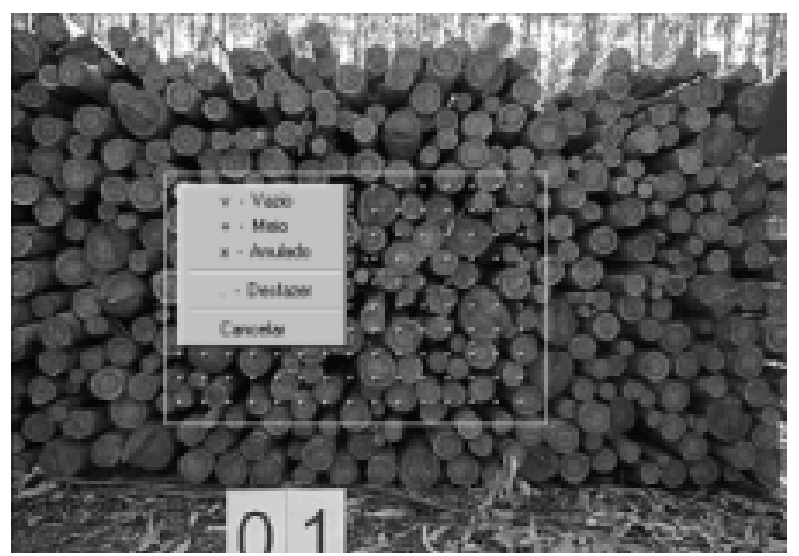

Figura 2 - Classificação dos pontos sobre a fotografia pelo Digitora.

Figure 2 - Classification of the points on photographs by Digitora software.

R. Árvore, Viçosa-MG, v.27, n.6, p.837-844, 2003 
As estimativas dos fatores, obtidas pelo método fotográfico nas 30 pilhas, foram comparadas com as estimativas dos fatores observados, pelo teste " $t$ " para dados pareados, considerando o nível de $95 \%$ de probabilidade.

Além disso, foram avaliados: a) a precisão do método fotográfico em relação aos fatores observados, através do cálculo da média dos desvios porcentuais (MDP); e b) o efeito do número de repetições sobre as estimativas médias dos fatores de empilhamento e o comportamento dos fatores de empilhamento em relação aos diâmetros das toras das pilhas, através de análise gráfica e do teste " $\mathrm{t}$ " para amostras independentes.

\section{RESULTADOS E DISCUSSÃO}

Analisando os dados no Quadro 1 e a Figura 3, verifica-se que os fatores de empilhamento observados variaram de 1,3842 a 1,2465, com tendência de diminuição do fator com o aumento do diâmetro médio das toras. Este resultado apresenta-se bem próximo daqueles encontrados por Rezende (1988), para pilhas construídas manualmente com madeira do gênero Eucalyptus.

Pode-se observar, ainda na Figura 3, a existência de dois grupos distintos: o primeiro possui um fator de empilhamento médio de 1,3162 e o segundo um fator de

Quadro 1 - Altura média da pilha $(H)$, comprimento médio das toras $(C)$, largura da pilha $(L)$, volume em estéreo $\left(V_{s t}\right)$, volume em metro cúbico $\left(V_{m}^{3}\right)$, fatores de empilhamento observados $\left(F_{e R}\right)$, número de toras $(n)$ e diâmetro quadrático das toras $(q)$

Table 1 - Average height of the stack $(\boldsymbol{H})$, average length of the logs $(\boldsymbol{C})$, width of the stack $(\boldsymbol{L})$, observed volume in stereo $\left(\boldsymbol{V}_{\text {st }}\right)$, observed volume in cubic meter $\left(\boldsymbol{V}_{\boldsymbol{m}^{3}}\right)$, observed piling factors $\left(\boldsymbol{F}_{\boldsymbol{e}}\right)$, number of logs (n) and quadratic diameter of the logs (q)

\begin{tabular}{|c|c|c|c|c|c|c|c|c|c|}
\hline Pilha & Face & $H(\mathrm{~m})$ & $C(\mathrm{~m})$ & $L(\mathrm{~m})$ & $V_{s t}$ & $V_{m^{3}}$ & $F_{e R}$ & $n$ & $q(\mathrm{~cm})$ \\
\hline \multirow{2}{*}{1} & A & 1,12 & 1 & 3 & 3,3600 & 2,4632 & 1,3641 & & \\
\hline & $\mathrm{B}$ & 1,15 & 1 & 3 & 3,4590 & 2,4632 & 1,4043 & & \\
\hline Média & & & 1 & 3 & 3,4095 & & 1,3842 & 305 & 9,4989 \\
\hline \multirow{2}{*}{2} & A & 1,22 & 1 & 3 & 3,6630 & 2,7099 & 1,3517 & & \\
\hline & B & 1,25 & 1 & 3 & 3,7440 & 2,7099 & 1,3816 & & \\
\hline Média & & & 1 & 3 & 3,7035 & & 1,3666 & 301 & 9,8591 \\
\hline \multirow{2}{*}{3} & A & 1,14 & 1 & 3 & 3,4320 & 2,6269 & 1,3065 & & \\
\hline & B & 1,14 & 1 & 3 & 3,4230 & 2,6269 & 1,3031 & & \\
\hline Média & & & 1 & 3 & 3,4275 & & 1,3048 & 306 & 9,6285 \\
\hline \multirow{2}{*}{4} & $\mathrm{~A}$ & 1,23 & 1 & 3 & 3,6840 & 2,7641 & 1,3328 & & \\
\hline & $\mathrm{B}$ & 1,26 & 1 & 3 & 3,7800 & 2,7641 & 1,3675 & & \\
\hline Média & & & 1 & 3 & 3,7320 & & 1,3501 & 311 & 9,8394 \\
\hline \multirow{2}{*}{5} & A & 1,22 & 1 & 3 & 3,6450 & 2,7999 & 1,3018 & & \\
\hline & B & 1,27 & 1 & 3 & 3,8130 & 2,7999 & 1,3618 & & \\
\hline Média & & & 1 & 3 & 3,7290 & & 1,3318 & 307 & 9,9719 \\
\hline \multirow{2}{*}{6} & A & 1,26 & 1 & 3 & 3,7710 & 2,8999 & 1,3004 & & \\
\hline & B & 1,28 & 1 & 3 & 3,8430 & 2,8999 & 1,3252 & & \\
\hline Média & & & 1 & 3 & 3,8070 & & 1,3128 & 317 & 9,9965 \\
\hline \multirow{2}{*}{7} & A & 1,21 & 1 & 3 & 3,6180 & 2,8103 & 1,2874 & & \\
\hline & B & 1,24 & 1 & 3 & 3,7080 & 2,8103 & 1,3194 & & \\
\hline Média & & & 1 & 3 & 3,6630 & & 1,3034 & 320 & 9,7441 \\
\hline \multirow{2}{*}{8} & A & 1,22 & 1 & 3 & 3,6570 & 2,832 & 1,2913 & & \\
\hline & $\mathrm{B}$ & 1,24 & 1 & 3 & 3,7050 & 2,832 & 1,3082 & & \\
\hline Média & & & 1 & 3 & 3,6810 & & 1,2998 & 312 & 9,9369 \\
\hline \multirow{2}{*}{9} & A & 1,24 & 1 & 3 & 3,7050 & 2,901 & 1,2771 & & \\
\hline & $\mathrm{B}$ & 1,27 & 1 & 3 & 3,8190 & 2,901 & 1,3164 & & \\
\hline Média & & & 1 & 3 & 3,7620 & & 1,2968 & 337 & 9,6747 \\
\hline \multirow{2}{*}{10} & A & 1,35 & 1 & 3 & 4,0410 & 3,1397 & 1,2871 & & \\
\hline & $\mathrm{B}$ & 1,39 & 1 & 3 & 4,1730 & 3,1397 & 1,3291 & & \\
\hline Média & & & 1 & 3 & 4,1070 & & 1,3081 & 365 & 9,6949 \\
\hline \multirow{2}{*}{11} & A & 1,25 & 1 & 3 & 3,7470 & 2,9347 & 1,2768 & & \\
\hline & B & 1,29 & 1 & 3 & 3,8640 & 2,9347 & 1,3167 & & \\
\hline Média & & & 1 & 3 & 3,8055 & & 1,2967 & 329 & 9,8881 \\
\hline
\end{tabular}


Quadro 1, cont.

Table 1, cont.

\begin{tabular}{|c|c|c|c|c|c|c|c|c|c|}
\hline Pilha & Face & $H(\mathrm{~m})$ & $C(\mathrm{~m})$ & $L(\mathrm{~m})$ & $V_{s t}$ & $V_{m^{3}}$ & $F_{e R}$ & $n$ & $q(\mathrm{~cm})$ \\
\hline \multirow{2}{*}{12} & $\mathrm{~A}$ & 1,21 & 1 & 3 & 3,6270 & 2,8442 & 1,2752 & & \\
\hline & B & 1,26 & 1 & 3 & 3,7890 & 2,8442 & 1,3322 & & \\
\hline Média & & & 1 & 3 & 3,7080 & & 1,3037 & 295 & 10,3073 \\
\hline \multirow{2}{*}{13} & $\mathrm{~A}$ & 1,29 & 1 & 3 & 3,8610 & 2,8675 & 1,3464 & & \\
\hline & B & 1,26 & 1 & 3 & 3,7920 & 2,8675 & 1,3224 & & \\
\hline Média & & & 1 & 3 & 3,8265 & & 1,3344 & 325 & 9,7900 \\
\hline \multirow{2}{*}{14} & A & 1,20 & 1 & 3 & 3,6120 & 2,8227 & 1,2796 & & \\
\hline & B & 1,22 & 1 & 3 & 3,6630 & 2,8227 & 1,2977 & & \\
\hline Média & & & 1 & 3 & 3,6375 & & 1,2887 & 304 & 10,0749 \\
\hline \multirow{2}{*}{15} & A & 1,20 & 1 & 3 & 3,5970 & 2,829 & 1,2715 & & \\
\hline & B & 1,22 & 1 & 3 & 3,6450 & 2,829 & 1,2884 & & \\
\hline Média & & & 1 & 3 & 3,6210 & & 1,2799 & 315 & 9,8690 \\
\hline \multirow{2}{*}{16} & A & 1,27 & 1 & 3 & 3,8070 & 2,9254 & 1,3013 & & \\
\hline & B & 1,32 & 1 & 3 & 3,9450 & 2,9254 & 1,3485 & & \\
\hline Média & & & 1 & 3 & 3,8760 & & 1,3249 & 331 & 9,8075 \\
\hline \multirow{2}{*}{17} & A & 1,23 & 1 & 3 & 3,6870 & 2,9122 & 1,2661 & & \\
\hline & B & 1,27 & 1 & 3 & 3,8190 & 2,9122 & 1,3114 & & \\
\hline Média & & & 1 & 3 & 3,7530 & & 1,2887 & 328 & 9,8289 \\
\hline \multirow{2}{*}{18} & A & 1,33 & 1 & 3 & 4,0020 & 3,2176 & 1,2438 & & \\
\hline & B & 1,39 & 1 & 3 & 4,1550 & 3,2176 & 1,2913 & & \\
\hline Média & & & 1 & 3 & 4,0785 & & 1,2676 & 275 & 11,4911 \\
\hline \multirow{2}{*}{19} & A & 1,26 & 1 & 3 & 3,7920 & 3,0476 & 1,2442 & & \\
\hline & B & 1,31 & 1 & 3 & 3,9150 & 3,0476 & 1,2846 & & \\
\hline Média & & & 1 & 3 & 3,8535 & & 1,2644 & 261 & 11,4624 \\
\hline \multirow{2}{*}{20} & A & 1,22 & 1 & 3 & 3,6720 & 2,9609 & 1,2402 & & \\
\hline & B & 1,25 & 1 & 3 & 3,7500 & 2,9609 & 1,2665 & & \\
\hline Média & & & 1 & 3 & 3,7110 & & 1,2534 & 241 & 11,7897 \\
\hline \multirow{2}{*}{21} & A & 1,23 & 1 & 3 & 3,6900 & 2,9093 & 1,2684 & & \\
\hline & B & 1,25 & 1 & 3 & 3,7350 & 2,9093 & 1,2838 & & \\
\hline Média & & & 1 & 3 & 3,7125 & & 1,2761 & 238 & 11,7492 \\
\hline \multirow{2}{*}{22} & A & 1,23 & 1 & 3 & 3,7020 & 3,0000 & 1,2340 & & \\
\hline & B & 1,27 & 1 & 3 & 3,8100 & 3,0000 & 1,2700 & & \\
\hline Média & & & 1 & 3 & 3,7560 & & 1,2520 & 251 & 11,5532 \\
\hline \multirow{2}{*}{23} & $\bar{A}$ & 1,20 & 1 & 3 & 3,6000 & 2,9291 & 1,2291 & & \\
\hline & B & 1,23 & 1 & 3 & 3,7020 & 2,9291 & 1,2639 & & \\
\hline Média & & & 1 & 3 & 3,6510 & & 1,2465 & 240 & 11,7230 \\
\hline \multirow{2}{*}{24} & A & 1,25 & 1 & 3 & 3,7470 & 2,9686 & 1,2622 & & \\
\hline & B & 1,25 & 1 & 3 & 3,7530 & 2,9686 & 1,2642 & & \\
\hline Média & & & 1 & 3 & 3,7500 & & 1,2632 & 249 & 11,5702 \\
\hline \multirow{2}{*}{25} & $\mathrm{~A}$ & 1,24 & 1 & 3 & 3,7290 & 2,974 & 1,2539 & & \\
\hline & B & 1,24 & 1 & 3 & 3,7260 & 2,974 & 1,2529 & & \\
\hline Média & & & 1 & 3 & 3,7275 & & 1,2534 & 244 & 11,7139 \\
\hline \multirow{2}{*}{26} & A & 1,25 & 1 & 3 & 3,7440 & 2,963 & 1,2636 & & \\
\hline & B & 1,26 & 1 & 3 & 3,7890 & 2,963 & 1,2788 & & \\
\hline Média & & & 1 & 3 & 3,7665 & & 1,2712 & 250 & 11,5402 \\
\hline 27 & $\bar{A}$ & 1,24 & 1 & 3 & 3,7170 & 2,9775 & 1,2484 & & \\
\hline 27 & B & 1,27 & 1 & 3 & 3,8010 & 2,9775 & 1,2766 & & \\
\hline Média & & & 1 & 3 & 3,7590 & & 1,2674 & 250 & 11,5655 \\
\hline 28 & $\mathrm{~A}$ & 1,20 & 1 & 3 & 3,6090 & 2,8941 & 1,2470 & & \\
\hline & B & 1,21 & 1 & 3 & 3,6390 & 2,8941 & 1,2574 & & \\
\hline Média & & & 1 & 3 & 3,6240 & & 1,2522 & 241 & 11,6019 \\
\hline 20 & A & 1,21 & 1 & 3 & 3,6420 & 2,9404 & 1,2386 & & \\
\hline 29 & B & 1,24 & 1 & 3 & 3,7200 & 2,9404 & 1,2651 & & \\
\hline Média & & & 1 & 3 & 3,6810 & & 1,2519 & 254 & 11,4112 \\
\hline 30 & A & 1,33 & 1 & 3 & 3,9960 & 3,2176 & 1,2419 & & \\
\hline & B & 1,36 & 1 & 3 & 4,0830 & 3,2176 & 1,2690 & & \\
\hline Média & & & 1 & 3 & 4,0395 & & 1,2554 & 275 & 11,4911 \\
\hline
\end{tabular}


empilhamento médio de 1,2596. Este comportamento justificou-se pela necessidade de verificar o efeito do diâmetro das toras sobre o fator de empilhamento. Assim sendo, a partir de um dado momento, as pilhas foram montadas intencionalmente, com toras de diâmetros maiores, para esta análise. Pelo teste " $t$ " para amostras independentes, considerando o nível de $95 \%$ de probabilidade, verificou-se que os fatores de empilhamento médios para os dois grupos de dados diferem estatisticamente $\left(\mathrm{t}_{\text {calculado }}=7,63 ; \mathrm{t}(5 \%, 20 \mathrm{gl})=2,086\right)$, ou seja, a montagem intencional das pilhas surtiu o efeito desejado.

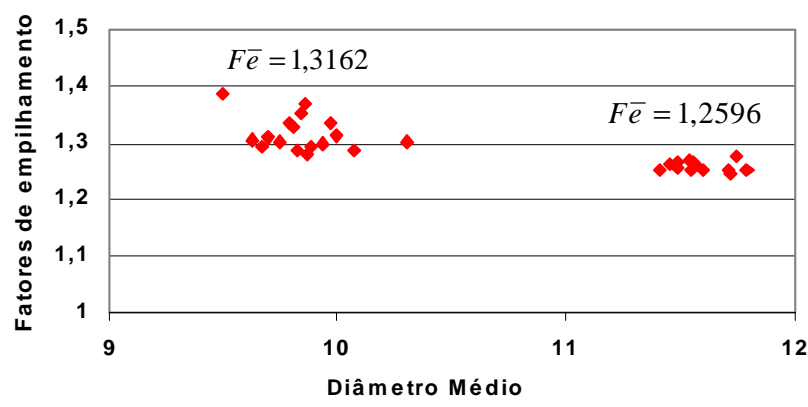

Figura 3 - Fatores de empilhamento observados em função do diâmetro médio das toras das pilhas.

Figure 3 -Observed piling factors in function of the quadratic diameter of the stacked logs.

A Figura 4 apresenta a relação entre os fatores de empilhamento com casca estimados e o diâmetro médio das toras das pilhas, na qual se verifica também a existência de dois grupos distintos, como mostrado na Figura 3. Pela aplicação do teste " $t$ " para amostras independentes, considerando o nível de $95 \%$ de probabilidade, verificouse que os fatores de empilhamento médios estimados para os dois grupos de dados diferiram estatisticamente $\left(\mathrm{t}_{\text {calculado }}\right.$ $=2,07 ; \mathrm{t}(5 \%, 28 \mathrm{gl})=2,048)$. Com isto, quanto maior o diâmetro das toras, menor o fator de empilhamento, o que pode ser constatado nos resultados apresentados anteriormente na Figura 3.

Em complemento às análises já realizadas, elaborouse um gráfico relacionando a diferença porcentual entre os fatores de empilhamento obtidos pelo operador $1 \mathrm{e}$ os fatores observados, em função do diâmetro médio das toras das pilhas (Figura 5), com o objetivo de verificar a relação entre o diâmetro das toras e a exatidão dos fatores obtidos pelo procedimento fotográfico. Analisando a Figura 5, verifica-se que o método fotográfico subestimou os fatores para as pilhas com toras de menores diâmetros

R. Árvore, Viçosa-MG, v.27, n.6, p.837-844, 2003 e tende a superestimar os fatores de empilhamento para as pilhas de maiores diâmetros.

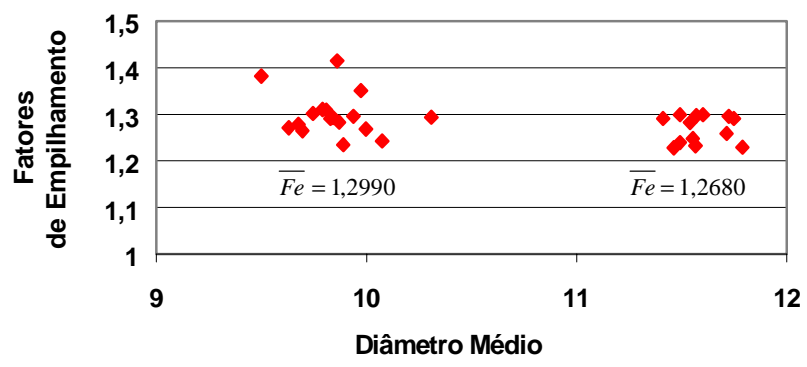

Figura 4 - Fatores de empilhamento estimados em função do diâmetro médio (quadrático) das toras das pilhas.

Figure 4 -Estimated piling factors in function of the quadratic diameter of the pile logs.

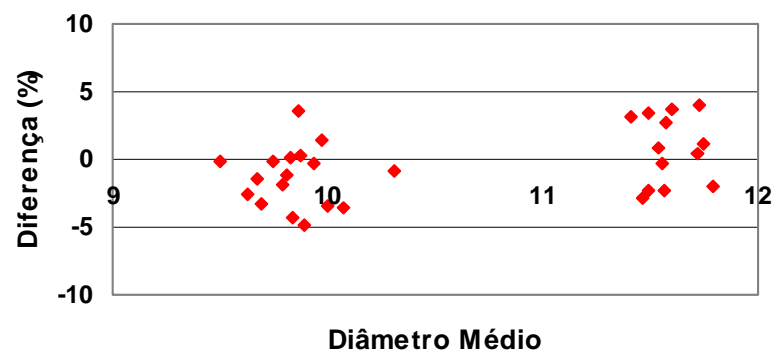

Figura 5 - Diferenças porcentuais entre os fatores de empilhamento obtidos pelo operador 1 e os observados em função do diâmetro médio (quadrático) das toras das pilhas.

Figure 5 - Percentile differences among the piling factors obtained by operator 1 and the observed piling factors in function of the quadratic diameter of the piled logs.

O fator de empilhamento, determinado pelo método fotográfico, pode ser obtido ao distribuir a rede de pontos sobre a foto apenas uma vez ou pela média aritmética de várias repetições. Para avaliar o comportamento das estimativas dos fatores de empilhamento em função do número de repetições sobre a foto, foram selecionadas três pilhas (pilhas 1,12 e 20), com base no diâmetro médio das toras da pilha, tendo sido realizadas dez repetições em cada uma. Assim sendo, foram obtidas as diferenças porcentuais entre os valores dos fatores de empilhamento observados com casca e os fatores de empilhamento médios, obtidos com diferentes números de repetições pelo operador 1 (mais treinado).

Analisando as Figuras 6, 7 e 8, verifica-se que, de modo geral, um maior número de repetições tende a 


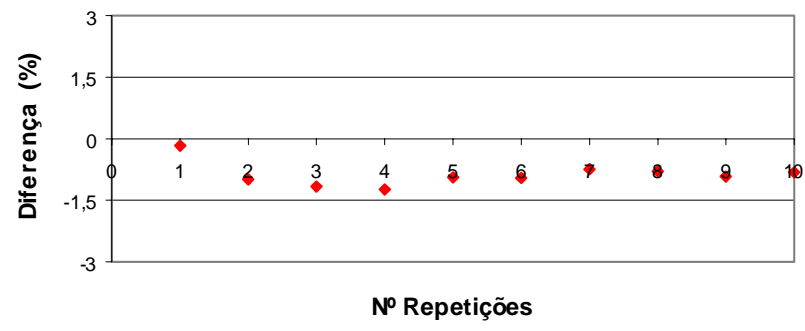

Figura 6 - Diferenças porcentuais entre os fatores de empilhamento observados e os fatores de empilhamento médios, obtidos com diferentes números de repetições (Pilha 1).

Figure 6 -Percentile differences among the observed piling factors and the average piling factors, obtained with different numbers of repetitions (Pile 1).

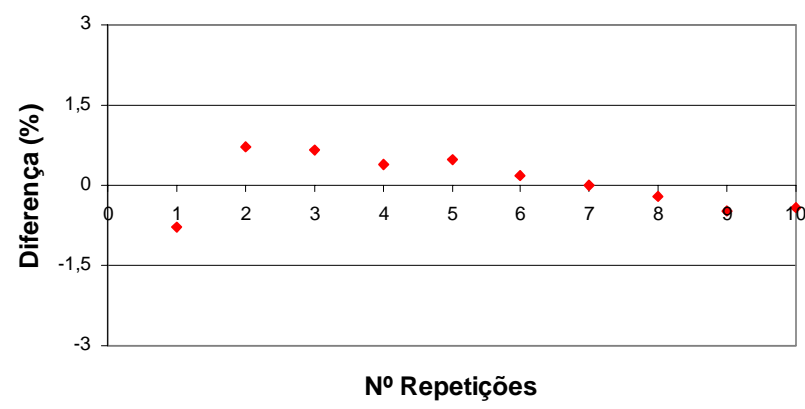

Figura 7 - Diferenças porcentuais entre os fatores de empilhamento observados e os fatores de empilhamento médios, obtidos com diferentes números de repetições (Pilha 12).

Figure 7 -Percentile differences among the observed piling factors and the average piling factors, obtained with different numbers of repetitions (Pile 12).

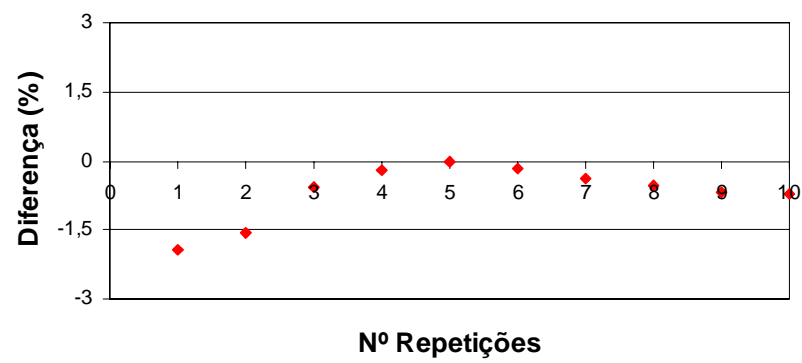

Figura 8 - Diferenças porcentuais entre os fatores de empilhamento observados e os fatores de empilhamento médios, obtidos com diferentes números de repetições (Pilha 20).

Figure 8-Percentile differences among the observed piling factors and the medium piling factors, obtained with different numbers of repetitions (Pile 20). diminuir a diferença entre os verdadeiros valores dos fatores de empilhamento e os obtidos pelo procedimento fotográfico, mesmo o operador estando bem treinado com o software DIGITORA. No entanto, pela tendência apresentada, não há a necessidade de um número excessivamente grande de repetições, haja vista que a partir da quarta repetição as diferenças permaneceram praticamente constantes e próximo de zero. Constata-se nas Figuras 6 e 8, que mesmo aumentando o número de repetições, houve tendência de subestimação dos fatores de empilhamento.

\section{CONCLUSÕES}

Para uso do software DIGITORA há necessidade de treinamento do "fotointérprete" do programa, no que concerne às regras de identificação das toras na imagem. As fotos deverão ser sempre tomadas com o flash ligado, independentemente das condições de luminosidade existentes, para melhor visualização da face da pilha. A câmera a ser utilizada deve estar com o ZOOM ativado, o que deverá diminuir o efeito de perspectiva (conicidade) nas extremidades das fotografias.

A média dos desvios porcentuais entre os fatores de empilhamento obtidos pelas fotos e os fatores reais, para o operador mais treinado, foi da ordem de - $0,424 \%$. Embora a média dos desvios porcentuais tenha sido próximo de zero, houve uma leve tendência de superestimação dos fatores.

$\mathrm{O}$ fator de empilhamento decresce para as maiores classes de diâmetro, ou seja, quanto maior o diâmetro das toras, menor o fator de empilhamento.

Os fatores de empilhamentos médios, obtidos por repetições em uma mesma foto, apresentaram-se mais precisos do que os fatores obtidos de apenas uma observação.

\section{REFERÊNCIAS BIBLIOGRÁFICAS}

ANDRADE, V. C. L.; LEITE, H. G. Um método para quantificar multiprodutos de árvores individuais na unidade estére. Revista Árvore, v. 22, n. 3, p. 299-306, 1998.

ASSOCIATION OF FOREST ENGINEERS FOR THE PROVINCE OF QUEBEC. Studies of the board foot, cubic foot and cord units of wood measurement. Journal of Forestry, v. 27, p. 913-928, 1928.

R. Árvore, Viçosa-MG, v.27, n.6, p.837-844, 2003 
BRUCE, D.; SCHUMACHER, F. X. Forest mensuration New York: Mc Graw-Hill, 1950. 438 p.

COUTO, H. T. Z.; BASTOS, N. L. M. Fator de empilhamento para plantações de eucaliptos no Estado de São Paulo. Revista IPEF, n. 38, p. 23-27, 1988.

GARLAND, H. Using polaroid camera to measure trucked hardwood pulpwood. Pulp and Paper Magazine, v. 69, n. 8, p. 86-87, 1968.

HUSCH, B.; MILLER, C. I.; BEERS, T. W. Forest mensuration. 2.ed. New York: John Willey \& Sons, 1972. $410 \mathrm{p}$.

KEEPERS, C. A. H. New method of measuring the actual volume of wood in stacks. Journal of Forestry, v. 43. p. 16-22, 1945.

MOUNTAIN, H. S. Determining the solid wood volume of four-foot pulpwood stacks. Journal of Forestry, v. 47, p. $627-631,1949$.
PAULA NETO, F.; REZENDE, A. V. Equações de fatores de empilhamento e tabelas de volumes em metros estere para árvores individuais. Revista Árvore, v. 16, n. 1, p. 72-87, 1992.

REZENDE, A. V. Análise dos métodos de estimação do volume sólido da madeira e do comportamento do fator de empilhamento para Eucalyptus grandis. 1988. $131 \mathrm{f}$.

Dissertação (Mestrado em Ciência Florestal) - Universidade Federal de Viçosa, Viçosa-MG, 1988.

RUBIO, M. E. L. Comparación de diferentes métodos para él calculo de coeficientes de apilamiento en bruzuelo, raya y troza de medidas comerciales. México: Instituto Nacional de Investigaciones Forestales, 1982. 64 p. (Boletim Técnico, 82).

SCHNUR, G. L. Converting factors some stacked cords. Journal of Forestry, n. 30, p. 814-820, 1932.

SCOLFORO, J. R.; FILHO, A. F. Mensuração florestal 2: Volumetria. Lavras: ESAL/FAEPE. p. 106-114, 1992.

ZON, R. Factors influencing the volume of solid wood in the cord. Quartely Journal of Forest, n. 1, p. 126-133, 1903. 